\title{
Abstract \\ Hereditary Breast Cancer in Latvia: Mutation Analysis of the BRCA1 Gene
}

\author{
L. Tihomirova ${ }^{1}$, B. Csokay $^{2}$, A. Stengrevics ${ }^{3}$, \\ O. Sinicka ${ }^{1}$, R. Kamerade ${ }^{1}$ and E. Olah ${ }^{2}$ \\ ${ }^{1}$ Biomedical Research and Study Centre, \\ University of Latvia, Riga, Latvia \\ ${ }^{2}$ National Institute of Oncology, Department \\ of Molecular Biology, Budapest, Hungary \\ ${ }^{3}$ Latvian Oncology Center, Riga, Latvia
}

Breast cancer is the main cause of death from malignant diseases in Latvian women. However, there have been no data concerning hereditary breast cancer from this region so far. Mutation screening of the breast cancer susceptibility genes BRCA1 and BRCA2 in high-risk Hungarian and Russian breast/ovarian cancer families indicated that founder effects of both genes in Central and Eastern Europe are considerable (Ramus, S.J. et al. 1997; Gayther, S.A. et al. 1997). In this study we determined the spectrum of BRCA1 mutations in 23 breast cancer patients treated at the Latvian Oncology Center in the period of 1995 to 1998 . The entire coding region and splice sites of the BRCA1 gene were screened for mutations using SSCP,

\begin{abstract}
Heteroduplex Analysis and Protein Truncation Test followed by direct sequencing. The family histories in our cases were considerably less pronounced than those in other studies of highrisk families: 5 patients were considered to be members of high-risk families ( 3 or more breast cancers and/or 1 ovarian cancer in the family), 10 patients were from moderate risk families (2 cases in family) and 8 early onset breast cancer patients ( $<40$ yrs.) reported no family history. Three different mutations (5382insC, Cys61Gly and $4153 \mathrm{del}$ A ) have been identified in 8 patients out of 23 examined. Interestingly, most 5382insC mutations were identified in patients of Russian nationality. One hundred additional incident breast cancer patients have been screened for exons 5 and 20 of BRCA1 and two more 5382insC mutations were identified, both patients were of Russian nationality. Results of p53 mutation frequency in sporadic breast cancer patients and BRCA1 mutation carriers as well as data on erbB-2/neu amplification will also be presented. Predominance of a limited number of founder mutations in Latvian patients facilitates identification of mutation carriers in this population.
\end{abstract}




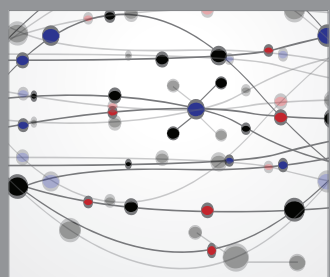

The Scientific World Journal
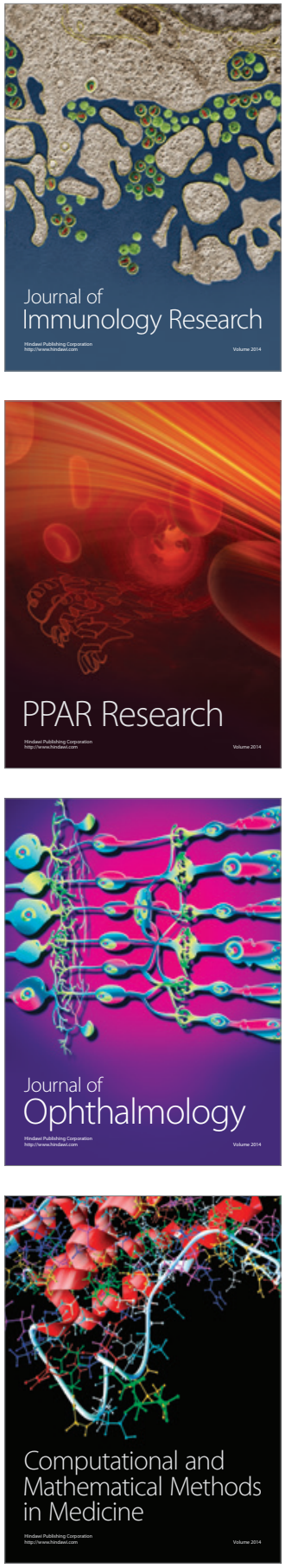

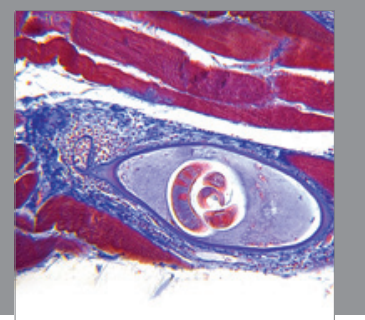

Gastroenterology

Research and Practice
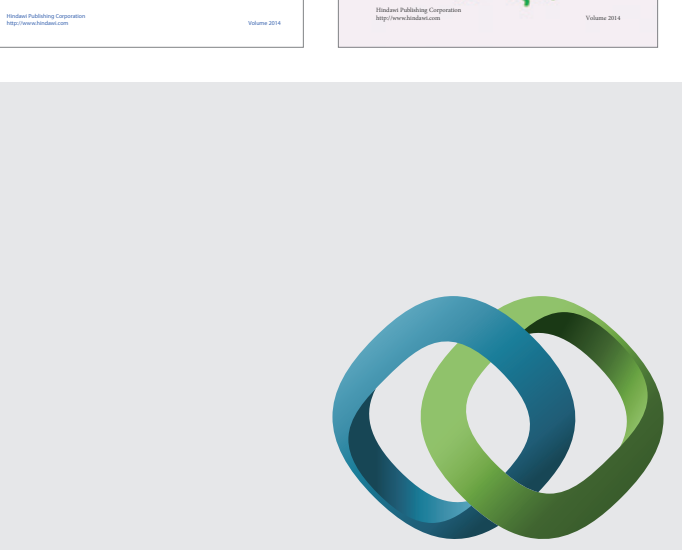

\section{Hindawi}

Submit your manuscripts at

http://www.hindawi.com
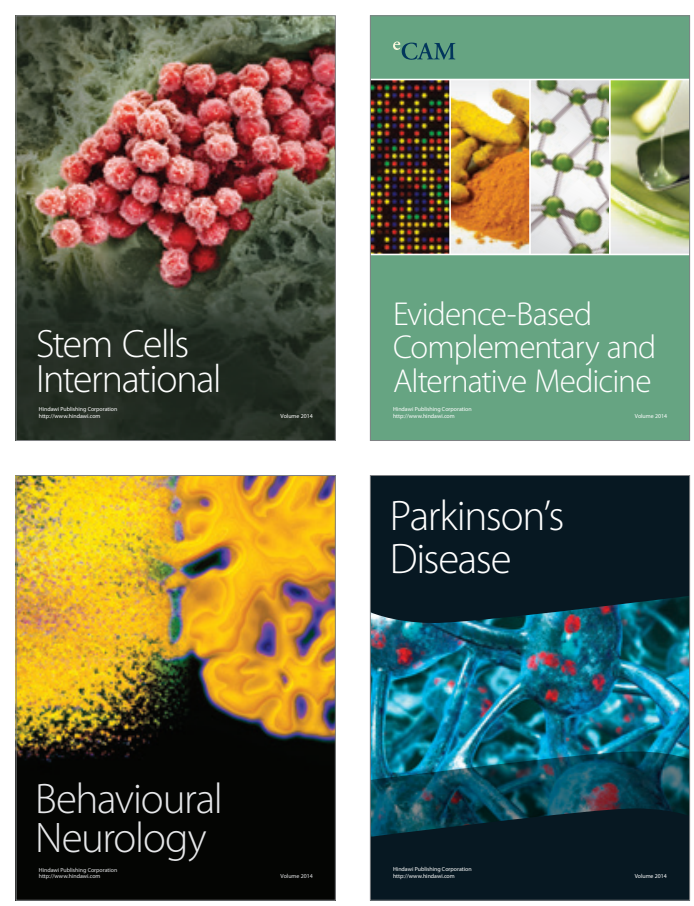

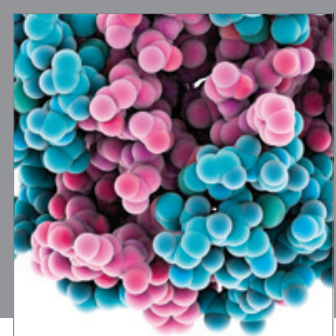

Journal of
Diabetes Research

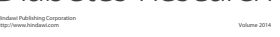

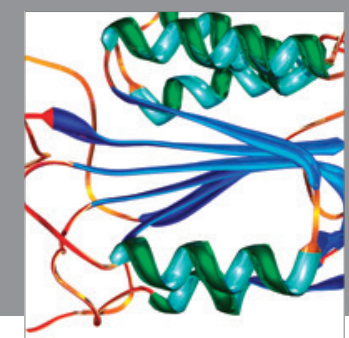

Disease Markers
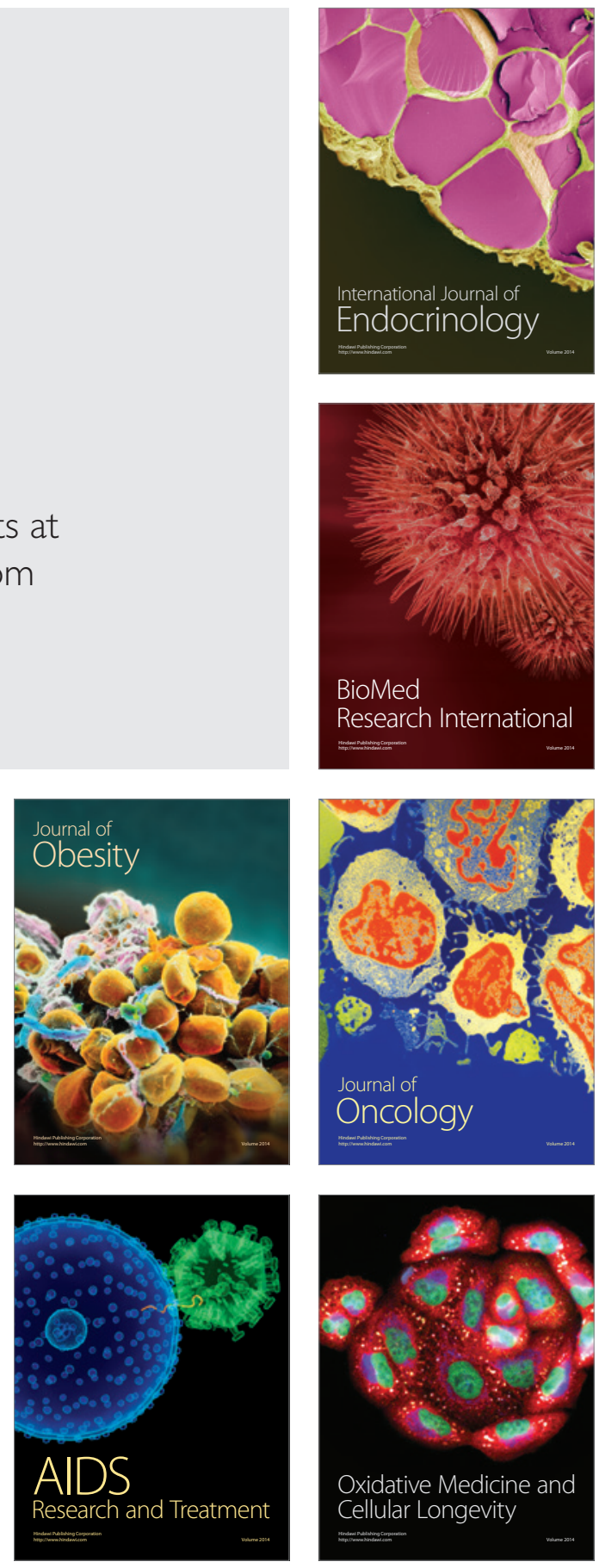